\title{
Montmorillonite impregnated with bismuth nitrate: a versatile reagent for the synthesis of nitro compounds of biological significance
}

\author{
Susanta Samajdar, Frederick F. Becker, and Bimal K. Banik* \\ The University of Texas, M. D. Anderson Cancer Center, Department of Molecular Pathology, \\ Box 89, 1515 Holcombe Blvd., Houston, TX 77030, USA. \\ E-mail: banik@mdanderson.org
}

Dedicated to Professor T. R. Govindachari on the occasion of his $85^{\text {th }}$ birthday

(received 10 May 01; accepted 08 Aug 01; published on the web 16 Aug 01)

\begin{abstract}
Montmorillonite impregnated with bismuth nitrate has been found to be an excellent reagent for the synthesis of several nitro compounds of biological significance in high yield.
\end{abstract}

Keywords: Montmorillonite, bismuth nitrate, surface mediated reactions, nitrating agents

\section{Introduction}

Surface-mediated organic reactions are undergoing extensive investigation especially because they are ecologically friendly. ${ }^{1}$ The usefulness of clay mediated organic synthesis has been documented in a large number of recent publications. ${ }^{2}$ For example, montmorillonite which is commercially available has shown considerable promise as a solid support in carrying out different chemical reactions. ${ }^{2}$ Based on our own work on bismuth ${ }^{3}$ salts, we became interested in exploring trivalent bismuth nitrate as the nitrating agent under solid support. These experiments culminated in a facile synthetic method of aromatic nitration of several aromatic hydrocarbons by bismuth nitrate supported on montmorillonite which takes taking only a few minutes. ${ }^{4}$ In continuation of bismuth nitrate mediated aromatic nitration, we report here the synthesis and characterization of several biologically active aromatic nitro compounds not only with polyaromatic hydrocarbons, but also with steroids and $\beta$-lactams.

\section{Results and Discussion}

\section{Polyaromatic Nitro Compounds}

Polyaromatic nitro compounds are widespread in the environment. We have been engaged in the 
development of aromatic compounds as anti-tumor agents and have shown structure-activity relationships with several diamides and diamines to which a polycyclic aromatic ring was bound. ${ }^{5}$ The nitro compounds required for the synthesis of these types of derivatives were prepared by the conventional nitric acid-sulfuric acid or nitroniun tetrafluoborate methods. We became concerned about the disposal of the large amount of acid-waste that resulted. To avoid this complication and the associated hazards, we set out to test the nitrating abilities of nitratesalts under solid phase conditions in a projected route to develop a simple synthesis of the aromatic nitro compound in a relatively short period of time.

Montmorillonite clay impregnated with anhydrous cupric nitrate termed as "claycop" was used for aromatic nitration reaction. ${ }^{6}$ A large excess of acetic anhydride was required when claycop was used as the nitrating agent. The actual nitrating species was believed to be acetyl nitrate. Similarly, a clay with ferric nitrate termed as "clayfen" was used as the reagent for the nitration of estrone, though yields were poor. ${ }^{7}$ In addition, extreme precautions were necessary for the preparation of this reagent. ${ }^{8}$ Sulfuric acid supported on silica gel that catalyzed nonselective nitration of simple aromatic compounds has also been reported. ${ }^{9}$

Mixing the starting materials with bismuth nitrate and montmorillonite with tetrahydrofuran and evaporation of the solvent under rotavapor comprise the reaction conditions for successful, regiospecific nitration with several aromatic compounds including multicyclic ring systems. The nitration of aromatic compounds by our method is shown in Scheme 1. A comparison with other solid supports, such as silica gel, acidic alumina, and ground molecular sieves was also carried out. Anisole 1, naphthalene 2, fluorene 3, chrysene 4, and dibenzofluorene 5 were regiospecifically converted to the corresponding nitro compounds $\mathbf{6}$ through $\mathbf{1 0}$ by bismuth nitrate-montmorillonite in excellent yield. Interestingly, the site of the electrophilic attack by this reagent was found to be identical to the conventional nitric acid or acetyl nitrate mediated nitration reaction (Scheme 1).

The reaction of naphthalene 2 using silica gel as support under identical conditions as described with montmorillonite failed to produce the nitro derivative although the same mixture upon microwave irradiation ${ }^{10}$ afforded the 1 -nitronaphthalene 7 in $70 \%$ yield. Acidic alumina and molecular sieves alone failed to give any product with or without acid. The results indicated that montmorillonite is the solid support of choice for aromatic nitration.

Steroids: At the beginning of the nitration study on steroid, a model reaction was investigated. Phenol 11 produced a mixture of 2- and 4-nitrophenol 12 and 13 in a ratio of 1:3. The formation of the mixture of nitro derivatives $\mathbf{1 2}$ and $\mathbf{1 3}$ with phenolic substrates indicated lesser selectivity under this condition (Scheme 2). 


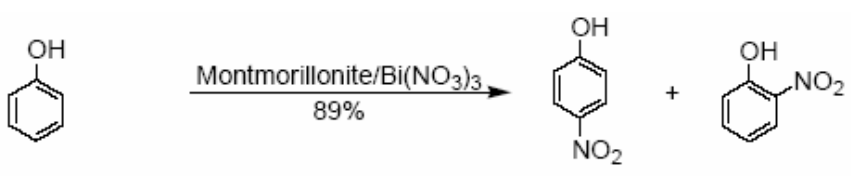

11<smiles>CC12CCC3c4ccc(O)cc4CCC3C1CCC2=O</smiles>

14
$13 \quad 12$

$3: 1$<smiles>CC12CCC3c4ccc(O)c([N+](=O)[O-])c4CCC3C1CCC1C3CCC4C(=O)CCC4C3CCC12</smiles>

15

$1: 1$<smiles>COc1ccc([N+](=O)[O-])cc1</smiles>

1

$\underset{91 \%}{\stackrel{\text { Montmorillonite/Bi }\left(\mathrm{NO}_{3}\right)_{3}}{\longrightarrow}}$<smiles>COc1ccccc1</smiles>

(<smiles>c1ccc2ccccc2c1</smiles>

$\underset{\text { Montmorillonite/Bi( }\left(\mathrm{NO}_{3}\right)_{3}}{\stackrel{\text { P }}{\longrightarrow}}$

2<smiles>c1ccc2c(c1)Cc1ccccc1-2</smiles>

3<smiles>c1ccc2c(c1)ccc1c3ccccc3ccc21</smiles>

4<smiles>FC12Cc3ccc4ccccc4c3C1c1ccc3ccccc3c12</smiles>

5 $\underset{\text { Montmorillonite/Bi( }\left(\mathrm{NO}_{3}\right)_{3}}{\stackrel{92 \%}{\longrightarrow}}$

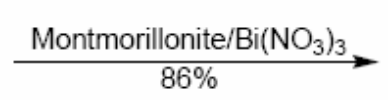
$86 \%$

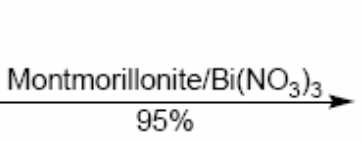

10

\section{Scheme 1}
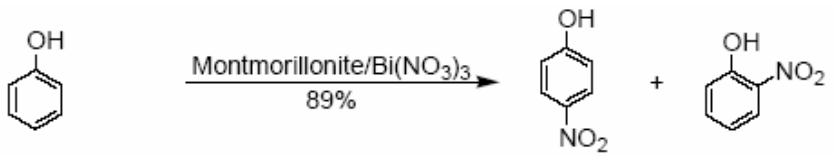

13

12<smiles>CC12CCC3c4ccc(O)cc4CCC3C1CCC2=O</smiles>

Montmorillonite/Bi $\left(\mathrm{NO}_{3}\right)_{3}$<smiles>CC12CCC3c4cc([N+](=O)[O-])c(O)cc4CCC3C1CCC2=O</smiles>

15<smiles>CC12CCC3c4ccc(O)c([N+](=O)[O-])c4CCC3C1CCC2=O</smiles>
16

14

$1: 1$

Scheme 2 
In order to confirm the reactivity of phenolic substrates, we carried out nitration of estrone 14 with bismuth nitrate--montmorillonite with the goal of synthesizing the biologically active 2- or 4-nitro estrones 15 and 16. In conformity with our results with phenolic substrates, the reaction produced a mixture of 2-nitro and 4-nitro estrones $\mathbf{1 5}$ and $\mathbf{1 6}$ in a ratio of 1:1 in 94\% yield. The nitration of estrone by freshly prepared clayfen using bentonite $\mathrm{K}-10$ demonstrated the production of $2-$ nitroestrone $\mathbf{1 5}$ in $55 \%$ yield by stirring the reaction mixture in toluene for overnight. $^{7}$ However, when we followed this procedure, we isolated a mixture of 2-nitro 15 and 2,4-dinitro estrones in 90\% yield (12 h).

$\beta$-Lactams: The bismuth nitrate mediated nitration was then extended for a facile synthesis of nitro substituted $\beta$-lactams. Suitably substituted hydroxy $\beta$-lactams on a coupling reaction with commercially available baccatin can produce Taxol and Taxotere. ${ }^{11}$ Structure-activity study of Taxol and Taxotere with a nitro group at the $\mathrm{C}-13$ side chain has not been investigated. Synthesis of nitro-substituted $\beta$-lactams by acid chloride-imine cyclization reaction (Staudinger reaction $)^{12}$ provides $\beta$-lactam in low yield. ${ }^{13}$ Considering the potentiality of nitro substituted $\beta$-lactam and the mild conditions associated with our present investigation, we undertook nitration study by bismuth nitrate. By following an identical procedure as described above, the cis-acetoxy $\beta$-lactam 17 produced a mixture of two nitro $\beta$-lactams 18 and 19 within minutes in low yield (60\%) and no side reaction, i.e., cleavage of the ring, oxidation of the aromatic system or the deprotection of the ester group was observed (Scheme 3). However, a considerable amount of starting material remained intact. A brief exposure of microwave irradiation to the solid mass helped to increase the yields of the products (94\%). The structure of the products 18 and 19 were deduced from the nmr spectra. Only the aromatic group that has the methoxy group was attacked. ${ }^{14}$ Reaction with trans- $\beta$-lactam 20 also afforded two compounds 21 and 22 (1:2) in excellent yield (Scheme 4).

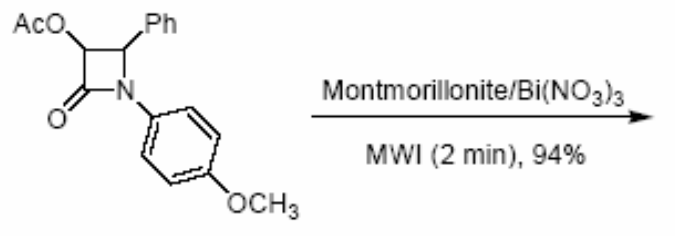

17

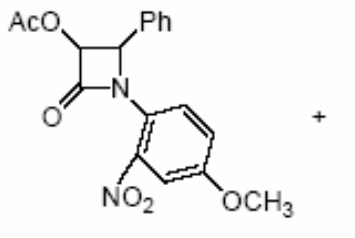

18

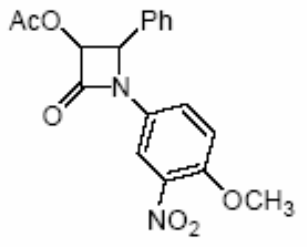

19

$\mathrm{MWI}=$ microwave irradiation

$1: 2$

\section{Scheme 3}

Direct synthesis of nitro-substituted $\beta$-lactam by acid chloride 23-imine 24 cyclization reaction (Staudinger reaction) ${ }^{12}$ provides 21 in low yield (Scheme 5). Since annulation with nitroimines 24 afforded trans $\beta$-lactams 21, this present method by bismuth nitrate reaction is of considerable value for the synthesis of cis-substituted nitro $\beta$-lactams 18 and 19. 


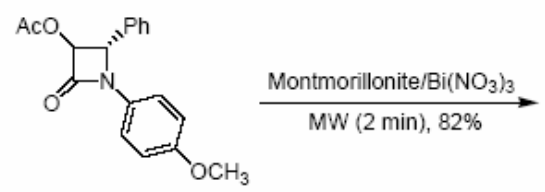

20

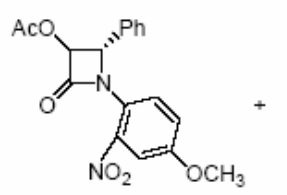

21

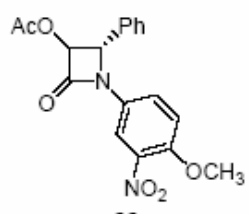

22

\section{Scheme 4}

Our results indicate that the nitration reaction depends strongly on the nature of the solid support. Further, two solid adsorbents of identical structure with different surface area (particle size) can give different product distribution. Based on a recent publication, ${ }^{15}$ we believe that the binding of bismuth nitrate to the free hydroxyl group of the multi-metallic montmorillonite is important and that this complex produces the nitronium ion. Clearly, the failure of bismuth nitrate to produce any product with alumina and only $70 \%$ with silica gel (under microwave irradiation), despite the presence of surface hydroxyl groups, strengthens the importance of the composition of the solid support.

\section{Scheme 5}

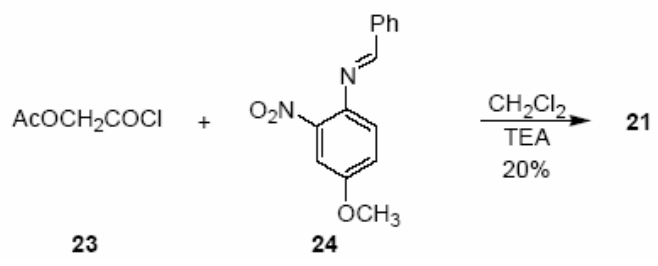

In summary, we have shown a simple, rapid and convenient method for the aromatic nitration with bismuth nitrate in the presence of montmorillonite at room temperature. The superiority of this method over others includes a very rapid reaction (approximate 30 minutes instead of 24 hour) with readily available reagents. Further, our method requires no strong acid, ${ }^{16}$ no acetic anhydride and it can be applied to a wide range of substrates and results in high overall yield.

\section{Experimental Section}

General Procedures. All reactions described in this paper were carried out under a wellventilated hood. IR spectra were recorded on a Perkin-Elmer Spectrum 2000 instrument. NMR spectra were recorded on Bruker $300 \mathrm{MHz}$ spectrometer. Chemical shifts were reported as $\delta$ values in parts per million downfield from $\mathrm{t}$ e $\mathrm{t} \mathrm{ra} \mathrm{m}$ e $\mathrm{t} \mathrm{h}$ yl silane as the internal standard in $\mathrm{CDCl}_{3}$. Elemental analysis was performed by Schwarzkopf Microanalytical Laboratory, Inc., New York. Melting points were taken in open capillary tube and are not corrected. Column chromatography was carried out with Aldrich silica gel (230 mesh). TLC was run with precoated silica gel plate.

The compound to be nitrated ( $1 \mathrm{mmol}$ ) and Montmorillonite KSF (500 mg, Aldrich) were added to a suspension of bismuth nitrate $(1 \mathrm{mmol})$ in THF $(10 \mathrm{~mL})$. The solvent was then evaporated 
under reduced pressure and dried in the vacuum pump for 5 min (in some cases the mixture needed microwave irradiation for 2 min to complete the reaction). The mixture was then repeatedly washed with dichloromethane (ca $25 \mathrm{~mL}$ ) and it was concentrated to afford the crude product. The pure product was isolated after column chromatography and by crystallization.

Compounds 6 to9, 12 and 13 are known (Aldrich Chemical Company) and these gave identical physico-chemical data with respect to authentic compounds.

The procedure for the nitration of $\beta$-lactams is different than the method described above.

Analytical data of 10, 15 and $\mathbf{1 6}$ are reported in earlier publications. ${ }^{5 \mathrm{~b}, 7}$

Cis-1-N-(2-Nitro-4-methoxy)-phenyl-3-acetoxy-4-phenyl-2-azetidinone (18) and $\mathrm{Cis}-1-\mathrm{N}$-(3Nitro-4-methoxy)-phenyl-3-acetoxy-4-phenyl-2-azetidinone (19). The compound 17 (311 mg, $1 \mathrm{mmol}$ ) and Montmorillonite KSF (500 mg, Aldrich) were added to a suspension of bismuth nitrate pentahydrate $(485 \mathrm{mg}, 1 \mathrm{mmol})$ in THF $(10 \mathrm{~mL})$. The solvent was then evaporated under reduced pressure and irradiated in a kitchen microwave for $2 \min$ (Using 50\% power level). The mixture was then repeatedly washed with dichloromethane (ca $25 \mathrm{~mL}$ ) and it was concentrated to afford a mixture of two regio-isomeric mono nitro derivatives. The pure products were isolated after column chromatography. The compound obtained in the earlier fraction $(10 \%$ ethyl acetate$90 \%$ hexane) was found to be $18(110 \mathrm{mg}, 31 \%)$; mp $150{ }^{\circ} \mathrm{C} ;{ }^{1} \mathrm{H}$ NMR $\left(\mathrm{CDCl}_{3}\right) \delta 7.48(1 \mathrm{H}, \mathrm{d}, J$ $=8.97 \mathrm{~Hz}), 7.37-7.33(6 \mathrm{H}, \mathrm{m}), 7.08(1 \mathrm{H}, \mathrm{dd}, J=2.89 \mathrm{~Hz}, 8.95 \mathrm{~Hz}), 5.99(1 \mathrm{H}, \mathrm{d}, J=4.8 \mathrm{~Hz})$, $5.51(1 \mathrm{H}, \mathrm{d}, J=4.9 \mathrm{~Hz}), 3.82(3 \mathrm{H}, \mathrm{s}), 1.72(3 \mathrm{H}, \mathrm{s})$; IR (neat) 1756, 1538, 1505, $1222 \mathrm{~cm}^{-1}$. Anal. Calcd for $\mathrm{C}_{18} \mathrm{H}_{16} \mathrm{~N}_{2} \mathrm{O}_{6}$ : C, 60.7\%; H, 4.5\%; N, 7.9\%. Found: C, 60.33; H, 4.56; N, 7.90. The compound obtained in the latter fraction was found to be $19(225 \mathrm{mg}, 67 \%) ; \mathrm{mp} 152{ }^{\circ} \mathrm{C} ;{ }^{1} \mathrm{H}$ NMR (CDCl3) $\delta 7.76(1 \mathrm{H}, \mathrm{d}, J=2.65 \mathrm{~Hz}), 7.56(1 \mathrm{H}, \mathrm{dd}, J=2.68 \mathrm{~Hz}, 8.96 \mathrm{~Hz}), 7.37-7.29(5 \mathrm{H}$, m), $7.01(1 \mathrm{H}, \mathrm{d}, J=9.08 \mathrm{~Hz}), 5.98(1 \mathrm{H}, \mathrm{d}, J=4.93 \mathrm{~Hz}), 5.39(1 \mathrm{H}, \mathrm{d}, J=4.93 \mathrm{~Hz}), 3.90(3 \mathrm{H}, \mathrm{s})$, $1.69(3 \mathrm{H}, \mathrm{s})$; IR (neat) 1756, 1534, 1505, $1222 \mathrm{~cm}^{-1}$. Anal. Calcd for $\mathrm{C}_{18} \mathrm{H}_{16} \mathrm{~N}_{2} \mathrm{O}_{6}: \mathrm{C}, 60.7 ; \mathrm{H}$, $4.5 \%$; N, 7.9\%. Found: C, 60.30; H, 4.45; N, 7.89.

Trans-1-N-(2-Nitro-4-methoxy)-phenyl-3-acetoxy-4-phenyl-2-azetidinone. (21) and Trans-1$\mathrm{N}$-(3-Nitro-4-methoxy)-phenyl-3-acetoxy-4-phenyl-2-azetidinone (22). Following the same procedure as above the compound 20 was converted to a mixture of 21 and 22 . 21 (23\%); mp $96{ }^{\circ} \mathrm{C} ;{ }^{1} \mathrm{H}$ NMR $\left(\mathrm{CDCl}_{3}\right) \delta 7.44-7.32(7 \mathrm{H}, \mathrm{m}), 7.06(1 \mathrm{H}, \mathrm{dd}, J=2.9 \mathrm{~Hz}, 8.9 \mathrm{~Hz}), 5.54(1 \mathrm{H}, \mathrm{d}, J$ $=2.0 \mathrm{~Hz}), 5.17(1 \mathrm{H}, \mathrm{d}, J=2.0 \mathrm{~Hz}), 3.80(3 \mathrm{H}, \mathrm{s}), 2.19(3 \mathrm{H}, \mathrm{s})$; IR (neat) 1757, 1535, 1505, 1221 $\mathrm{cm}^{-1}$.Anal. Calcd for $\mathrm{C}_{18} \mathrm{H}_{16} \mathrm{~N}_{2} \mathrm{O}_{6}: \mathrm{C}, 60.7 \% ; \mathrm{H}, 4.5 \%$; N, 7.9\%. Found: C, 60.40; H, 4.39; N, 7.87. 22 (55\%); mp $92{ }^{\circ} \mathrm{C} ;{ }^{1} \mathrm{H} \mathrm{NMR}\left(\mathrm{CDCl}_{3}\right) \delta 7.72(1 \mathrm{H}, \mathrm{d}, J=2.6 \mathrm{~Hz}), 7.51(1 \mathrm{H}, \mathrm{dd}, J=2.6$ $\mathrm{Hz}, 9.04 \mathrm{~Hz}), 7.447 .32(5 \mathrm{H}, \mathrm{m}), 7.01(1 \mathrm{H}, \mathrm{d} . J=9.06 \mathrm{~Hz}), 5.44(1 \mathrm{H}, \mathrm{d}, J=1.54 \mathrm{~Hz}), 4.99(1 \mathrm{H}$, d. $J=1.3), 3.91(3 \mathrm{H}, \mathrm{s}), 2.21(3 \mathrm{H}, \mathrm{s})$; IR (neat) 1756, 1533, 1505, $1219 \mathrm{~cm}^{-1}$.Anal. Calcd for $\mathrm{C}_{18} \mathrm{H}_{16} \mathrm{~N}_{2} \mathrm{O}_{6}$ : C, 60.7\%; H, 4.5\%; N, 7.9\%. Found: C, 60.42; H, 4.42; N,7.84.

\section{Acknowledgements}

We gratefully acknowledge the funding support received for this research project from the 
Golden Family Fund for cancer research and NIH Cancer Center Support Grant, 5-P30CA16672-25, in particular the shared resources of the Pharmacology and Analytic Center Facility.

\section{References and Notes}

1. For example, see: (a) Cornelis, A.; Delaude, L.; Gertmans, A.; Laszlo, P. Tetrahedron Lett. 1988, 29, 5657. (b) Laszlo, P.; Cornelis, A. Aldrichim. Acta 1988, 21, 97. (c) Laszlo, P.; Vandormael, J. Chem Lett. 1988, 1843. (d) Laszlo, P.; Cornelis, A.; Gerstmans, A.; Laszlo, P. Chem Lett. 1988, 1839.

2. Varma, R. S. Green Chem. 1999, 43 and references cited therein.

3. (a) Banik, B. K.; Venkatraman, M. S.; Mukhopadhyay, C.; Becker, F. F. Tetrahedron Lett. 1998, 39, 7243. (b) Banik, B. K.; Ghatak, A.; Venkatraman, M. S.; Becker, F. F. Synth. Commun. 2000, 30, 2701. (c) Banik, B. K. Ghatak, A.; Mukhopadhyay, C.; Becker, F. F. J. Chem. Res. (S), 2000, 108. (d) Samajdar, S., Becker, F. F., Banik, B. K. Synth. Commun. 2001, in press.

4. Samajdar, S.; Becker, F. F.; Banik, B. K. Tetrahedron Lett. 2000, 41, 8017.

5. (a) Becker, F. F.; Banik, B. K. Bioorganic \& Med. Chem. 1998, 50, 2877. (b) Becker, F. F.; Mukhopadhyay, C.; Hackfeld, L.; Banik, I.; Banik, B. K. Bioorg. \& Med. Chem. 2000, 8, 2693. (c) Banik, B. K.; Becker, F. F. Current Medicinal Chemistry 2001, in press. (d) Banik, B. K.; Becker, F. F. Bioorganic \& Med. Chem. 2001, 9, 593.

6. For nitration with claycop, see: Gigantee, B.; Prazeres, A. O.; Marcelo-Curto, M. J.; Cornelis, A.; Laszlo, P. J. Org. Chem. 1995, 60, 3445 and references cited therein.

7. Cornelis, A.; Laszlo, P.; Pennetreau, P. J. Org. Chem. 1983, 48, 4771.

8. Cornelis, A.; Laszlo, P. Synthesis 1985, 909.

9. Riego, J.; M. Sedin, Z.; Zaldivar, J. M.; Marziano, N. C.; Tortato, C. Tetrahedron Lett. 1996, 37,513

10. Microwave irradiation has been used in organic synthesis, for some examples, see: (a) Caddick, S. Tetrahedron 1995, 51, 10403. (b) Bose, A. K.; Banik, B. K.; Lavlinskaia, N.; Jayaraman, M.; Manhas, M. S. Chemtech 1997, 27, 18. (c) Mukhopadhyay, C.; Becker, F. F. Banik, B. K. J. Chem. Res. 2001, 28.

11. Suffness, M. Taxol Science and Applications., CRC Press, Boca Raton, 1995.

12. Banik, B. K.; Becker, F. F. Tetrahedron Lett. 2000, 41, 6551.

13. Just, G.; Vgolini, A.; Zamboni, R. Synth. Commun. 1979, 9, 117.

14. We thank Professor A. K. Bose for sharing their results with us.

15. Kropp, J. P.; Breton, G. W.; Fields, J. D.; Tung, J. C.; Loomis, B. R. J. Am. Chem. Soc. 2000, $122,4280$.

16. For some examples of aromatic nitration with mixed acids see: (a) Olah, G. A.; Malhotra, R.; Narang, S. C. In Nitration. Methods and Mechanisms, VCH Publishers: New York, 1989. (b) Schofield, K. In Aromatic Nitration, Cambridge University Press: Cambridge, 1980. 